\title{
A PGSE NMR Approach to the Characterization of Single and Multi-Site Halogen-Bonded
}

\section{Adducts in Solution $\dagger$}

Gianluca Ciancaleoni, ${ }^{\mathrm{a}, *}$ Alceo Macchioni, ${ }^{\mathrm{b}}$ Luca Rocchigiani, ${ }^{\mathrm{b}, \mathrm{c}}$ Cristiano Zuccaccia $^{\mathrm{b}}$

a Departamento de Química, Universidade Federal de Santa Catarina, 88040-900 Florianópolis, SC,Brazil.

${ }^{\mathrm{b}}$ Dipartimento di Chimica, Biologia e Biotecnologie, Universitá degli Studi di Perugia, Via Elce di Sotto 8, I-06123, Perugia,Italy

${ }^{\mathrm{c}}$ School of Chemistry, University of East Anglia, Norwich, NR4 7TJ, UK

*e-mail address: g.ciancaleoni@ufsc.br

$\dagger$ Electronic Supporting Information (ESI) available

\begin{abstract}
We demonstrate here that Pulsed field Gradient Spin Echo (PGSE) NMR diffusion technique can be effectively used as a complementary tool for the characterization of mono- and multi-site intermolecular halogen bonding $(\mathrm{XB})$ in solution. The main advantage of this technique is that it provides the possibility of unambiguously determining the stoichiometry of the supramolecular adduct, an information that is particularly important when multi-site molecular systems are studied. As an example, PGSE NMR measurements in chloroform indicate that hexamethylenetetramine (HMTA), a potentially four-sites XB acceptor, actually exploits only two sites for the interaction with the XB donor N-bromosuccinimide (NBS), leaving the other two nitrogen sites unoccupied. Charge Displacement calculations suggest that this is due also to the anticooperativity of the XB interaction between HMTA and NBS.
\end{abstract}




\section{Introduction}

Halogen bonding (XB), ${ }^{1}$ i.e. the non-covalent interaction between an halogen atom (XB donor) and a Lewis base (XB acceptor), mostly reveals its potential in solid state chemistry, being nowadays a powerful tool for the engineering of advanced materials ${ }^{2,3,4}$ and a relevant motif in the structure of biomolecules. ${ }^{5} \mathrm{XB}$ emerged also as an interesting topic for theoretical chemistry, which tried to determine, not without controversies, the relative weights of charge transfer, electrostatic, dispersion, and polarization effects to $\mathrm{XB} .{ }^{6}$ In the last few years, $\mathrm{XB}$ started to find intriguing applications even in solution, mainly in catalysis ${ }^{7}$ and anion recognition. ${ }^{8}$ As a consequence, the characterization of the supramolecular structure of XB adducts in solution and the determination of the formation equilibrium constants have assumed a higher importance, also because the pattern of intermolecular interaction in solution could differ from that found at the solid state.

Recently, it has been suggested ${ }^{9}$ that halogen bonding is not the only interaction that $\mathrm{XB}$ donors and acceptors can establish in solution, even when no other obvious interactions are possible, leading to adducts with different geometries but same stoichiometry. We recently demonstrated that ${ }^{19} \mathrm{~F},{ }^{1} \mathrm{H}$ HOESY NMR, previously exploited with success to investigate ion pairing ${ }^{10}$ and frustrated Lewis pairs, ${ }^{11}$ can be also exploited to disclose the intermolecular structure of XB adducts. ${ }^{12}$ Furthermore, in combination with theoretical studies, it can be used to estimate the relative weights of XB and non-XB interactions. ${ }^{12}$

Concerning the equilibrium constants involved in the $\mathrm{XB}$ interactions, many useful titration techniques have been applied ${ }^{13,14}$ and the choice of the best one (UV-Vis, IR, NMR...) depends on the nature of the system under investigation. In all cases, the presence of more interactions is a potential complication, because the effect of each interaction on the experimental observable is, in principle, of a different magnitude, and their disentanglement is not easy. An additional layer of complexity arises when multi-site acceptors and donors are taken into account. In this case, the exact nuclearity of the adduct should be known a priori, since the fitting equation depends on the stoichiometry of the adduct (except when the different aggregation steps are clearly consecutive and 
with very different affinities). ${ }^{14}$ Information about the latter can be derived from the Job's plot, but the general applicability of this technique is limited ${ }^{15}$ and its coupling with other methodologies is always desirable.

Here, we propose the diffusion Pulsed field Gradient Spin Echo (PGSE) ${ }^{16,17}$ NMR technique as a tool for the characterization of mono- and multi-site intermolecular halogen bonding systems, with the only requirement that NMR-active nuclei (preferably ${ }^{1} \mathrm{H},{ }^{19} \mathrm{~F}$ or ${ }^{31} \mathrm{P}$ ) are present on at least one, but preferably both, of the components. To the best of our knowledge, such a technique has been applied only in two recent cases, to support the formation of strong halogen-bonded adducts and to study the counterion influence on the same adduct. ${ }^{18,19}$

PGSE NMR allows information about the hydrodynamic volume $\left(V_{\mathrm{H}}\right)$ of molecular species in solution to be determined. ${ }^{17}$ In the case of an aggregation process, the measured $V_{\mathrm{H}}$ increases, allowing the estimation of the equilibrium constants $\left(K_{\mathrm{a}}\right)$ involved in the process. ${ }^{20}$ Remarkably, in the case of 1:1 adducts, the $K_{\mathrm{a}}$ can be evaluated by one single experiment, ${ }^{21}$ making it a useful tool for preliminary measurements.

Furthermore, since PGSE NMR is based exclusively on the $V_{\mathrm{H}}$, it takes into account all the possible aggregation processes, irrespectively from the supramolecular structure of the adduct. This offers the possibility to validate the data coming from titration techniques, where the effect of various interactions could be different on the chosen observable, with the general rule that $K_{\mathrm{a}}(\mathrm{PGSE}) \geq K_{\mathrm{a}}$ (titration). In addition, PGSE NMR is very useful when investigating symmetric multi-site XB donors or acceptors, since it gives directly the average size of the adducts and allows the determination of the average number of units that are interacting.

To illustrate the potential of the PGSE approach, we considered here Lewis acids and bases shown in Scheme 1, which already proved to be XB acceptors/donors, ${ }^{22}$ having different $\mathrm{XB}$ strength and number of sites. In particular, 1,4-diazabicyclo[2.2.2]octane (DABCO) and hexamethylenetetramine (HMTA) are commonly used in the fabrication of crystalline materials assembled by $\mathrm{XB}^{23}$ 


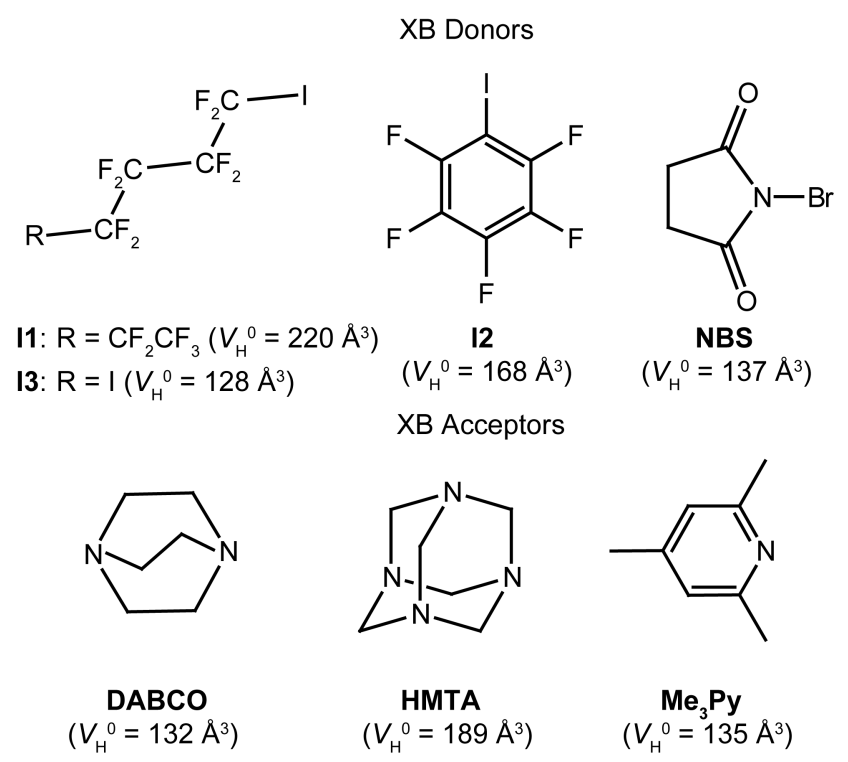

Scheme 1. XB donors and acceptors considered in this work. In parenthesis, the respective values for the hydrodynamic volume of the single molecule $\left(V_{\mathrm{H}}{ }^{0}\right)$ are reported.

In both cases, the number of nitrogen atoms involved in $\mathrm{XB}$ interactions depends on the $\mathrm{XB}$ donor and the crystallization conditions. 2,4,6-Trimethylpyridine ( $\left.\mathbf{M} \mathbf{e}_{3} \mathbf{P y}\right)$ is rarely used because the resulting $\mathrm{XB}$ adduct is very weak, so weak that other minor interactions, as lone pair/ $\pi$, cannot be neglected. ${ }^{12}$ On the other hand, perfluorinated alkanes and benzenes (as perfluorohexyl-1-iodide, I1, pentafluoroiodobenzene, I2 and 2,4-diiodooctafluorobutane, I3) have always been used in XB studies, ${ }^{24}$ whereas N-bromosuccinimide (NBS) only recently revealed its potential as XB donor. ${ }^{22 c}$

\section{Results and discussion}

The quantification of the hetero intermolecular aggregation by PGSE NMR asks for the preliminary evaluation of the hydrodynamic volume of the single molecule $\left(V_{\mathrm{H}}{ }^{0}\right)$ and their tendency to undergo self-aggregation.

For this reason, we initially performed PGSE NMR experiments on solutions of increasing concentration of the single components in toluene- $d_{8}$ or chloroform- $d$, obtaining concentrationindependent (within the experimental error of $\pm 10 \%$ ) values of $V_{\mathrm{H}}{ }^{0}$ equal to $220,168,128,137$, 
135, 132 and $189 \AA^{3}$ for I1, I2, I3, NBS, Me 3 Py, DABCO and HMTA, respectively (Table 1 and Scheme 1).

Table 1. Diffusion coefficients $\left(D_{\mathrm{t}}, 10^{-10} \mathrm{~m}^{2} \mathrm{~s}^{-1}\right)$, hydrodynamic radii $\left(r_{\mathrm{H}}, \AA\right)$ and hydrodynamic volumes $\left(V_{\mathrm{H}}, \AA^{3}\right)$ of pure $\mathbf{M e}_{3}$ Py, DABCO, I1 and $\mathbf{I} 2$ measured in toluene- $d_{8}$ and I3, HMTA and NBS in chloroform- $d$ at different concentrations $(C, \mathrm{mM})$.

\begin{tabular}{|c|c|c|c|}
\hline$C$ & $D_{\mathrm{t}}$ & $r_{\mathrm{H}}$ & $V_{\mathrm{H}}$ \\
\hline \multicolumn{4}{|c|}{$\mathbf{M e}_{3} \mathbf{P y}$} \\
\hline 3.1 & 16.1 & 3.18 & 135 \\
\hline 38.0 & 15.9 & 3.20 & 137 \\
\hline 175 & 16.2 & 3.18 & 135 \\
\hline 385 & 16.1 & 3.18 & 135 \\
\hline \multicolumn{4}{|c|}{ DABCO } \\
\hline 46.0 & 16.9 & 3.17 & 133 \\
\hline 262 & 17.2 & 3.14 & 130 \\
\hline \multicolumn{4}{|c|}{ I1 } \\
\hline 11.0 & 12.8 & 3.78 & 226 \\
\hline 123 & 12.9 & 3.70 & 212 \\
\hline 181 & 12.8 & 3.75 & 221 \\
\hline \multicolumn{4}{|c|}{ I2 } \\
\hline 17.4 & 15.3 & 3.37 & 160 \\
\hline 471 & 14.5 & 3.47 & 175 \\
\hline \multicolumn{4}{|c|}{$\mathbf{I 3}$} \\
\hline 19.0 & 14.1 & 3.11 & 126 \\
\hline 210.0 & 14.2 & 3.14 & 130 \\
\hline
\end{tabular}




\section{HMTA}

\begin{tabular}{lrrr}
19.0 & 12.0 & 3.54 & 187 \\
110 & 12.2 & 3.58 & 192 \\
& \multicolumn{3}{c}{ NBS } \\
5.4 & 14.3 & 3.20 & 137 \\
61.0 & 14.3 & 3.20 & 137
\end{tabular}

The hydrodynamic volume of any adduct can be calculated by the sum of the $V_{\mathrm{H}}{ }^{0}$ values of the constituents (Eq. 1), always under the spherical approximation. ${ }^{17}$

$$
V_{\mathrm{H}}^{\mathrm{agg}}(\mathrm{n} \mathbf{D}, \mathrm{mA})=\mathrm{n}^{*} V_{\mathrm{H}}^{0}(\mathbf{D})+\mathrm{m}^{*} V_{\mathrm{H}}^{0}(\mathbf{A})
$$

$\mathbf{M e}_{3} \mathbf{P y} / \mathbf{I 1}$. As stated in the Introduction, substituted pyridines usually afford quite weak XB interactions. As a confirmation, for an equimolar mixture of $\mathbf{M e}_{3} \mathbf{P y}$ and $\mathbf{I 1}$, the experimental hydrodynamic volumes of the two components $\left(V_{\mathrm{H}}\left(\mathbf{M e}_{3} \mathbf{P y}\right)\right.$ and $\left.V_{\mathrm{H}}(\mathbf{I} \mathbf{1})\right)$ are practically identical to the corresponding values of $V_{\mathrm{H}}^{0}$ (Table 2). For this reason, only when a large excess of one of the components is used the measured $\mathrm{V}_{\mathrm{H}}$ of the other component is significantly altered (Table 2). In particular, I1:Me $\mathbf{M} \mathbf{P y}$ molar ratios 1:3 or 1:14 are still not enough to have $V_{\mathrm{H}}(\mathbf{I 1})$ markedly different from its $V_{\mathrm{H}}{ }^{0}$, but using a molar ratio around to 1:200 leads to an increase of $\mathrm{V}_{\mathrm{H}}(\mathbf{I 1})$ from 220 to 340 $\AA^{3}\left(V_{\mathrm{H}}^{\mathrm{agg}}\left(\mathbf{M e}_{3} \mathbf{P y}, \mathbf{I 1}\right)=355 \AA^{3}\right)$. Being $\mathbf{M e} \mathbf{3} \mathbf{P y}$ in large excess, $V_{\mathrm{H}}\left(\mathbf{M e}_{\mathbf{3}} \mathbf{P y}\right)$ is clearly close to its $V_{\mathrm{H}}{ }^{0}$, since most of the molecules are not involved in the formation of aggregates. By applying equations S1 and S2 (Supporting Information) to the experimental data with the lowest I1:Me $\mathbf{P y}$ molar ratio (Table 2), a value of $K_{\mathrm{a}}=1.6 \pm 0.5 \mathrm{M}^{-1}$ is obtained.

Table 2. Diffusion coefficients $\left(D_{\mathrm{t}}, 10^{-10} \mathrm{~m}^{2} \mathrm{~s}^{-1}\right)$ and hydrodynamic volumes $\left(V_{\mathrm{H}}, \AA^{3}\right)$ of $\mathbf{M e} \mathbf{e}_{3} \mathbf{P y} / \mathbf{I 1}$ mixtures in toluene- $d_{8}$ at different concentrations $(C, \mathrm{mM})$. In all the cases, $C(\mathbf{I 1})=24 \mathrm{mM}$. 


\begin{tabular}{ccccc}
\hline$C\left(\mathbf{M e}_{3} \mathbf{P y}\right)$ & $D_{\mathrm{t}}\left(\mathbf{M e}_{3} \mathbf{P y}\right)$ & $D_{t}(\mathbf{I 1})$ & $V_{\mathrm{H}}\left(\mathbf{M e}_{3} \mathbf{P y}\right)$ & $V_{\mathrm{H}}(\mathbf{I 1})$ \\
\hline 24.9 & 16.1 & 12.9 & 146 & 219 \\
64.1 & 16.1 & 12.8 & 144 & 221 \\
346 & 16.1 & 12.4 & 146 & 232 \\
4910 & 15.7 & 10.3 & 152 & 340 \\
\hline
\end{tabular}

On the other hand, the ${ }^{19} \mathrm{~F}$ NMR titration method gives a value of $K_{\mathrm{a}}=0.85 \pm 0.01 \mathrm{M}^{-1}$ (Figure $\mathrm{S} 1$, Supporting Information). ${ }^{25}$ The titration allows to rapidly collect a large number of data, minimizing the experimental error. By the way, the formation constant obtained by diffusion measurements is double with respect to that obtained by the titration method, and this can be explained with the presence of two different 1:1 adducts, as already evidenced by HOESY results: ${ }^{12}$ the observable of the titration ( $\delta_{\mathrm{F}}$ of the $\alpha$ fluorine atoms, $-\mathrm{CF}_{2} \mathrm{I}$ ) is mainly influenced by the XB interaction established between the nitrogen of $\mathbf{M e}_{\mathbf{3}} \mathbf{P y}$ and the iodine of I1, whereas the observable of the PGSE $\left(\mathrm{V}_{\mathrm{H}}\right)$ is influenced by all the possible interactions, including electrostatic $\mathrm{H}^{\cdots} \mathrm{F}$ ones. ${ }^{12}$ Since the $K_{\mathrm{a}}$ estimated by the PGSE measurement is the sum of all the equilibrium constants active in solution, by coupling the two techniques we can conclude that the formation constant of non-XB adducts is approximately $0.75 \mathrm{M}^{-1}$.

Remarkably, also combining ${ }^{19} \mathrm{~F},{ }^{1} \mathrm{H}$ HOESY results with DFT calculations, the $\mathrm{XB}$ adducts resulted to be predominant over the non-XB ones $(\mathrm{XB}: \mathrm{non}-\mathrm{XB}=78: 22){ }^{12}$ considering the approximations used in that paper, a reasonably good agreement is obtained.

Interestingly, in the solid state only the XB can be detected, ${ }^{26}$ demonstrating that the supramolecular behavior of a pair in solution can differ from the structure of the same pair in the crystal.

DABCO/I1. In the case of multi-site XB acceptor, as DABCO is, the possibility of the 1:2 adduct must be taken into account. The symmetry of DABCO and the kinetic lability of XB in solution, hinder the possibility to use Overhauser-based experiments to determine how many nitrogen atoms 
are interacting with the Lewis acid. Also in this case, the investigation of non-stoichiometric mixtures is very informative. In fact, studying the pair $\mathbf{D A B C O / I 1}$ in the presence of an excess of DABCO makes the concentration of the 1:2 adduct negligible and the analysis of $V_{\mathrm{H}}(\mathbf{I 1})$ trends is related only to the formation of the 1:1 adduct $\left(K_{\mathrm{a} 1}\right)$. On the other side, information about $K_{\mathrm{a} 2}$ can be derived using an excess of $\mathbf{I 1}$.

Table 3. Diffusion coefficients $\left(D_{\mathrm{t}}, 10^{-10} \mathrm{~m}^{2} \mathrm{~s}^{-1}\right)$ and hydrodynamic volumes $\left(V_{\mathrm{H}}, \AA^{3}\right)$ of DABCO / I1 mixtures in toluene- $d_{8}$ at different concentrations $(C, \mathrm{mM})$.

\begin{tabular}{cccccc}
\hline$C($ DABCO $)$ & $\mathrm{C}(\mathbf{I 1})$ & $D_{\mathrm{t}}(\mathbf{D A B C O})$ & $D_{\mathrm{t}}(\mathbf{I 1})$ & $V_{\mathrm{H}}(\mathbf{D A B C O})$ & $V_{\mathrm{H}}(\mathbf{I 1})$ \\
\hline 3.6 & 20.0 & 12.8 & 12.3 & 221 & 239 \\
17.6 & 20.0 & 13.7 & 11.9 & 194 & 250 \\
108 & 20.0 & 15.1 & 10.3 & 162 & 328 \\
7.0 & 37.0 & 12.0 & - & 250 & - \\
7.0 & 85.0 & 10.5 & - & 326 & - \\
7.0 & 216 & 9.2 & - & 426 & - \\
7.0 & 343 & 8.5 & - & 517 & - \\
\hline
\end{tabular}

Maintaining $C(\mathbf{I 1})$ constant at $20 \mathrm{mM}$ (solvent: toluene- $\left.d_{8}\right)$ and increasing $C(\mathbf{D A B C O})$ from 3.6 to $108 \mathrm{mM}, V_{\mathrm{H}}(\mathbf{I 1})$ increases from 239 to $338 \AA^{3}$, whereas $V_{\mathrm{H}}(\mathbf{D A B C O})$ decreases from 221 to 162 $\AA^{3}$. As stated before, the effect of aggregation is more visible on the least abundant species, consequently when $C(\mathbf{D A B C O})<C(\mathbf{I 1}), V_{\mathrm{H}}(\mathbf{I 1})$ is just slightly larger than $V_{\mathrm{H}}{ }^{0}(\mathbf{I 1})$ and $V_{\mathrm{H}}(\mathbf{D A B C O})$ is markedly larger than $V_{\mathrm{H}}{ }^{0}(\mathbf{D A B C O})$. On the contrary, when $C(\mathbf{D A B C O})>C(\mathbf{I 1})$, the situation is the opposite, with $V_{\mathrm{H}}(\mathbf{D A B C O})$ similar to $V_{\mathrm{H}}{ }^{0}(\mathbf{D A B C O})$ and $V_{\mathrm{H}}(\mathbf{I 1})$ markedly higher than $V_{\mathrm{H}}{ }^{0}(\mathbf{I 1})$. Indeed, when the concentration ratio I1:DABCO is $20: 108, V_{\mathrm{H}}{ }^{0}(\mathbf{I 1})$ approaches $V_{\mathrm{H}}{ }^{\mathrm{agg}}(\mathbf{D A B C O}, \mathbf{I 1})$, which is $352 \AA^{3}$, evidencing an almost complete association of I1 under these conditions. 
Applying Eq. S1 and S2 (Supporting Information) to this single data, $K_{\mathrm{a} 1}$ was estimated to be $34 \pm$ $10 \mathrm{M}^{-1}$, which corresponds to a free energy of association $\left(\Delta G_{\mathrm{a} 1}\right)$ of $-2.1 \mathrm{kcal} / \mathrm{mol}$. The ${ }^{19} \mathrm{~F}$ NMR titration gives $K_{\mathrm{a} 1}=37.2 \pm 0.4 \mathrm{M}^{-1}$ (Figure S2, Supporting Information), in agreement within the experimental errors. ${ }^{27}$ In line with these findings, ${ }^{19} \mathrm{~F},{ }^{1} \mathrm{H}$ HOESY NMR data demonstrated that non-XB interactions can be neglected for this particular pair. ${ }^{12}$ Obviously, this does not mean that non-XB interactions are absent, but simply that their effects are completely hidden by the much more intense XB interaction, as in the PGSE as in the HOESY NMR experiments.

Successively, maintaining $C(\mathbf{D A B C O})$ at $7 \mathrm{mM}$ and increasing $C(\mathbf{I 1})$ from 37 to $343 \mathrm{mM}$, $V_{\mathrm{H}}(\mathbf{D A B C O})$ increases from 250 to $517 \AA^{3}$ (Table 3). In the last case, the hydrodynamic volume is much higher than $V_{\mathrm{H}}{ }^{0}(\mathbf{D A B C O})$, even higher than the volume of the $1: 1$ adduct $\left(352 \AA^{3}\right)$ and close to that of the 1:2 adduct $\left(V_{\mathrm{H}}^{\mathrm{agg}}(\mathbf{D A B C O}, 2 \mathbf{I 1})=572 \AA^{3}\right)$.

The data of $V_{\mathrm{H}}(\mathbf{D A B C O})$ as a function of $\mathrm{C}(\mathbf{I 1})$ can be fitted considering two equilibria (Figure 1 and equations S3 and S4, Supporting Information), ${ }^{15}$ either imposing $K_{\mathrm{a} 1}=34 \mathrm{M}^{-1}$, as determined previously, to find the best value of $K_{\mathrm{a} 2}$ or optimizing both $K_{\mathrm{a} 1}$ and $K_{\mathrm{a} 2}$. In the former case, $K_{\mathrm{a} 2}=5 \pm$ $1 \mathrm{M}^{-1}\left(\Delta G_{\mathrm{a} 2}=-0.9 \mathrm{kcal} / \mathrm{mol}\right)$; in the latter case, $K_{\mathrm{a} 1}=17 \pm 6 \mathrm{M}^{-1}$ and $K_{\mathrm{a} 2}=7 \pm 2 \mathrm{M}^{-1}$. The results of the two methodologies are qualitatively similar, even if the second one, having more degrees of freedom, better fits the experimental data (Figure 1). In any case, $K_{\mathrm{a} 2}$ is lower than $K_{\mathrm{a} 1}$. This is likely due to the low entropy of the adduct formed by three molecules.

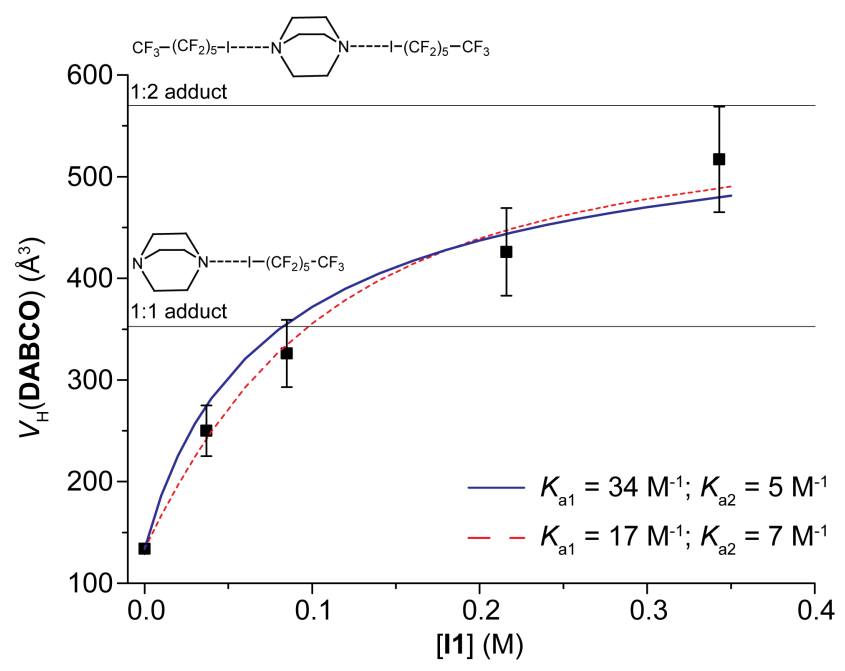


Figure 1. Experimental hydrodynamic volume of DABCO $(C=7 \mathrm{mM})$ at different concentrations of I1. The two lines represent the best fits obtained keeping $K_{\mathrm{a} 1}$ constant (solid blue line) or not (dashed red line). See text for the details.

More importantly, the PGSE results offer an immediate and intuitive insight into the nuclearity of the adducts, at each concentration ratio (Figure 1).

DABCO/I2. Three solutions of DABCO $(8.8 \mathrm{mM})$ in toluene- $d_{8}$ with increasing concentrations of I2 (44, 177 and $403 \mathrm{mM}$ ) have been studied (Table 4). Under these experimental conditions, $V_{\mathrm{H}}(\mathbf{D A B C O})$ spans from 194 to $352 \AA^{3}$, reaching a value that is in between $V_{\mathrm{H}}^{\text {agg }}(\mathbf{D A B C O}, \mathbf{I} 2)$ and $V_{\mathrm{H}}^{\mathrm{agg}}(\mathbf{D A B C O}, 2 \mathbf{I} 2)$. The fitting of the data, using $V_{\mathrm{H}}^{\mathrm{agg}}(\mathbf{D A B C O}, \mathbf{I 2})=303 \AA^{3}$ and $V_{\mathrm{H}}^{\mathrm{agg}}(\mathbf{D A B C O}$, $2 \mathbf{I} 2)=471 \AA^{3}$, leads to the values of $11.0 \pm 0.2$ and $2.1 \pm 0.1 \mathrm{M}^{-1}$ for $K_{\mathrm{a} 1}$ and $K_{\mathrm{a} 2}$, respectively $\left(\Delta G_{\mathrm{a} 1}\right.$ $=-1.5 \mathrm{kcal} / \mathrm{mol} ; \Delta G_{\mathrm{a} 2}=-0.4 \mathrm{kcal} / \mathrm{mol}$, Figure S3, Supporting Information).

Table 4. Diffusion coefficients $\left(D_{\mathrm{t}}, 10^{-10} \mathrm{~m}^{2} \mathrm{~s}^{-1}\right)$ and hydrodynamic volumes $\left(V_{\mathrm{H}}, \AA^{3}\right)$ of DABCO / I2 mixtures in toluene- $d_{8}$ at different concentrations $(C, \mathrm{mM})$.

\begin{tabular}{cccc}
\hline$C(\mathbf{D A B C O})$ & $C(\mathbf{I 2})$ & $D_{\mathrm{t}}(\mathbf{D A B C O})$ & $V_{\mathrm{H}}(\mathbf{D A B C O})$ \\
\hline 8.8 & 44.0 & 13.6 & 194 \\
8.8 & 177 & 11.2 & 286 \\
8.8 & 403 & 10.1 & 352 \\
\hline
\end{tabular}

HMTA/NBS. Crystallographic studies on the pairs HMTA/NIS (NIS = N-iodo-succinimide) and HMTA/NBS revealed many interesting properties of such systems. ${ }^{22 c}$ For example, in the former case all the four basic sites of HMTA interact with a molecule of NIS, while in the latter case only two nitrogen atoms interact with a molecule of NBS. Unfortunately, the solubility of the pair 
HMTA/NIS is not enough to allow a PGSE NMR study, but the pair HMTA/NBS is soluble enough in chloroform- $d$, even if very large excesses of one component cannot be explored.

For HMTA/NBS, the calculated hydrodynamic volumes for the 1:1, 1:2, 1:3 and 1:4 adducts are $323,457,591$ and $729 \AA^{3}$, respectively.

Table 5. Diffusion coefficients $\left(D_{\mathrm{t}}, 10^{-10} \mathrm{~m}^{2} \mathrm{~s}^{-1}\right)$ and hydrodynamic volumes $\left(V_{\mathrm{H}}, \AA^{3}\right)$ of HMTA / NBS mixtures in chloroform- $d$ at different concentrations $(C, \mathrm{mM})$.

\begin{tabular}{cccccc}
\hline$C($ HMTA $)$ & $C($ NBS $)$ & $D_{\mathrm{t}}($ HMTA $)$ & $D_{\mathrm{t}}(\mathbf{N B S})$ & $V_{\mathrm{H}}($ HMTA $)$ & $V_{\mathrm{H}}(\mathbf{N B S})$ \\
\hline 12.1 & 3.9 & 11.5 & 10.0 & 194 & 254 \\
50.0 & 3.9 & 11.9 & 8.36 & 166 & 291 \\
179 & 3.9 & 12.0 & 8.57 & 166 & 317 \\
2.1 & 4.3 & 10.4 & 12.8 & 217 & 150 \\
2.1 & 38.5 & 7.71 & 12.8 & 392 & 144 \\
2.1 & 56.0 & 7.62 & 13.7 & 408 & 130 \\
2.1 & $93.0^{\mathrm{a}}$ & 7.45 & 13.7 & 438 & 131 \\
\hline
\end{tabular}

${ }^{a}$ Saturated solution

Using chloroform- $d$ as solvent and keeping $C$ (NBS) fixed at $3.9 \mathrm{mM}$, three solutions with $C($ HMTA $)=12.1,50$ and $179 \mathrm{mM}$ have been analyzed. $V_{\mathrm{H}}(\mathbf{N B S})$ increases as $C($ HMTA $)$ increases, going from 254 to $317 \AA^{3}$ (Table 5), which is very close to $V_{\mathrm{H}}^{\text {agg }}$ (HMTA, NBS). Fitting the data, $K_{\mathrm{a} 1}$ results to be $161 \pm 27 \mathrm{M}^{-1}$ (Supporting Information).

In a second set of experiments, to a solution of HMTA $(C=2.1 \mathrm{mM})$ in chloroform- $d$, NBS was added to reach $C(\mathbf{N B S})=4.3,38.5,56$ and $93 \mathrm{mM}$ (Table 5). As before, the hydrodynamic volume of the component in excess decreases as its concentration increases $\left(V_{\mathrm{H}}(\mathbf{N B S})\right.$ goes from 150 to 131 $\AA^{3}$ ), whereas the hydrodynamic volume of the other component $\left(V_{\mathrm{H}}(\right.$ HMTA $\left.)\right)$ increases from 217 to $438 \AA^{3}$. Noteworthy, passing from $C($ NBS $)=56$ to $93 \mathrm{mM}, V_{\mathrm{H}}$ (HMTA) increases of only $30 \AA^{3}$, 
which is within the experimental error of $10 \%$. Unfortunately, a higher concentration of NBS is not possible because of the solubility limit of the mixture, but the final value of $V_{\mathrm{H}}($ HMTA) is very close to $V_{\mathrm{H}}^{\text {agg }}$ (HMTA, 2NBS). Such a value is the average of all the volumes of the species present in solution, but considering also that the trend of $V_{\mathrm{H}}$ (HMTA) vs. $C($ NBS) shows a plateau in the correspondence of $V_{\mathrm{H}}^{\mathrm{agg}}\left(\right.$ HMTA, 2NBS) (Figure 2), we can deduce that $K_{\mathrm{a} 3}$ and $K_{\mathrm{a} 4}$ are likely too small to be determined. Consequently, the experimental data can be fitted with the 1:2 model, in agreement with the crystal structure of this pair. ${ }^{22 \mathrm{c}}$ The absence of a plateau in this range of $V_{\mathrm{H}} \mathrm{S}$ (400-500 $\AA^{3}$ ) would have been an indication for the existence of larger adducts, as 1:3 and 1:4.

This reveals another great advantage of the diffusion NMR technique: for multi-site systems, the maximum stoichiometry is not a hypothesis, but can be derived from the trend of $V_{\mathrm{H}}$ with the concentration.

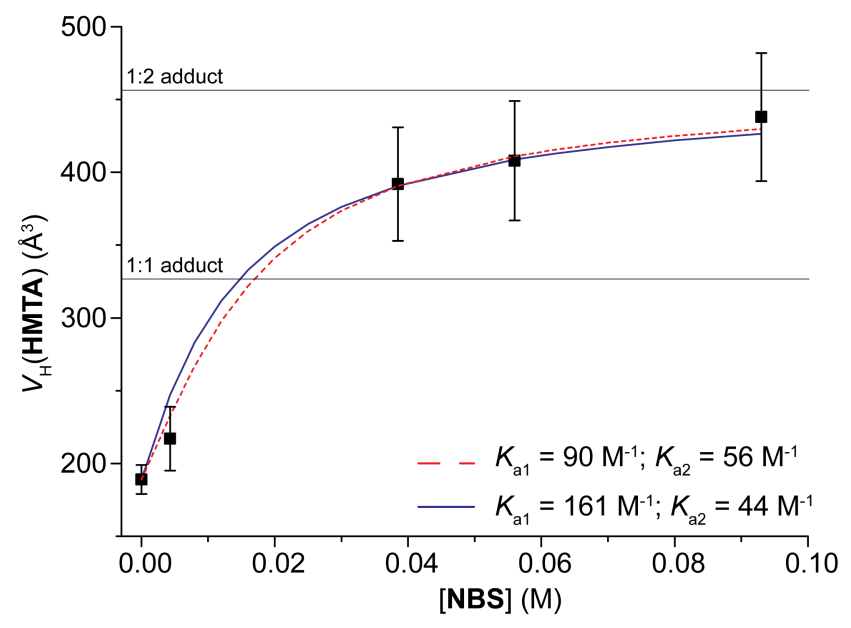

Figure 2. Experimental hydrodynamic volume of HMTA $(C=2.1 \mathrm{mM})$ at different concentrations of NBS. The two lines represent the best fits obtained keeping $K_{\mathrm{a} 1}$ constant (solid blue line) or not (dashed red line). See text for the details.

Fitting the experimental data with the 1:2 model and fixing $K_{\mathrm{a} 1}=161$, the best value of $K_{\mathrm{a} 2}$ is $44 \pm$ $12 \mathrm{M}^{-1}\left(\Delta G_{\mathrm{a} 2}=-2.2 \mathrm{kcal} / \mathrm{mol}\right)$, whereas optimizing both the values the results are $90 \pm 20$ and $56 \pm$ 
$8 \mathrm{M}^{-1}$ for $K_{\mathrm{a} 1}$ and $K_{\mathrm{a} 2}$, respectively $\left(\Delta G_{\mathrm{a} 1}=-2.6 \mathrm{kcal} / \mathrm{mol} ; \Delta G_{\mathrm{a} 2}=-2.4 \mathrm{kcal} / \mathrm{mol}\right)$. Also in this case, both methodologies give similar results and, again, $K_{\mathrm{a} 1}$ is larger than $K_{\mathrm{a} 2}$.

In order to understand better why the 1:3 adducts are not easily accessible in solution, DFT calculations have been performed on this system. Optimizing the structure of the 1:1, 1:2 and 1:3 adducts (level of theory M06-2X/def2-TZVP, as suggested by a recent, dedicated benchmark, ${ }^{28}$ see details in the Computational Details), the $\mathrm{N}^{\cdots} \mathrm{Br}$ distances results to be $2.533,2.585$ and $2.628 \AA$, respectively. The progressive lengthening of the $\mathrm{N}^{\cdots} \mathrm{Br}$ distance already indicates that the interaction is weaker as the number of NBS molecules around the central HMTA increases.

Other information can be obtained with the Charge Displacement (CD) method, ${ }^{29}$ which already proved to be useful for the characterization of coordinative ${ }^{30}$ and non-covalent bonds, ${ }^{11,31}$ including halogen bonding. ${ }^{32}$ In particular, $\mathrm{CD}$ results demonstrated to be correlated linearly to the formation constants of chalcogen bonded adducts. ${ }^{33}$

In the case of $1: 1$ adducts, the difference of electron density $(\Delta \rho)$ between the adduct and the separate fragments (HMTA and NBS) is shown in Figure 3a. It clearly shows that the nitrogen of HMTA is in a region of electron depletion, whereas a region of electron accumulation is present between the nitrogen and the bromine. As expected, a charge transfer between the two molecules exists, going from the nitrogen to the bromine. The latter shows a polarization pattern (depletion in the direction of HMTA, accumulation on the other side) and a remarkable region of electron accumulation is on the nitrogen of the NBS. The backbone of the NBS show a small charge accumulation, whereas the nitrogen atoms of the HMTA not involved in the XB show a small charge depletion, indication that the charge flux involve the entire system. 


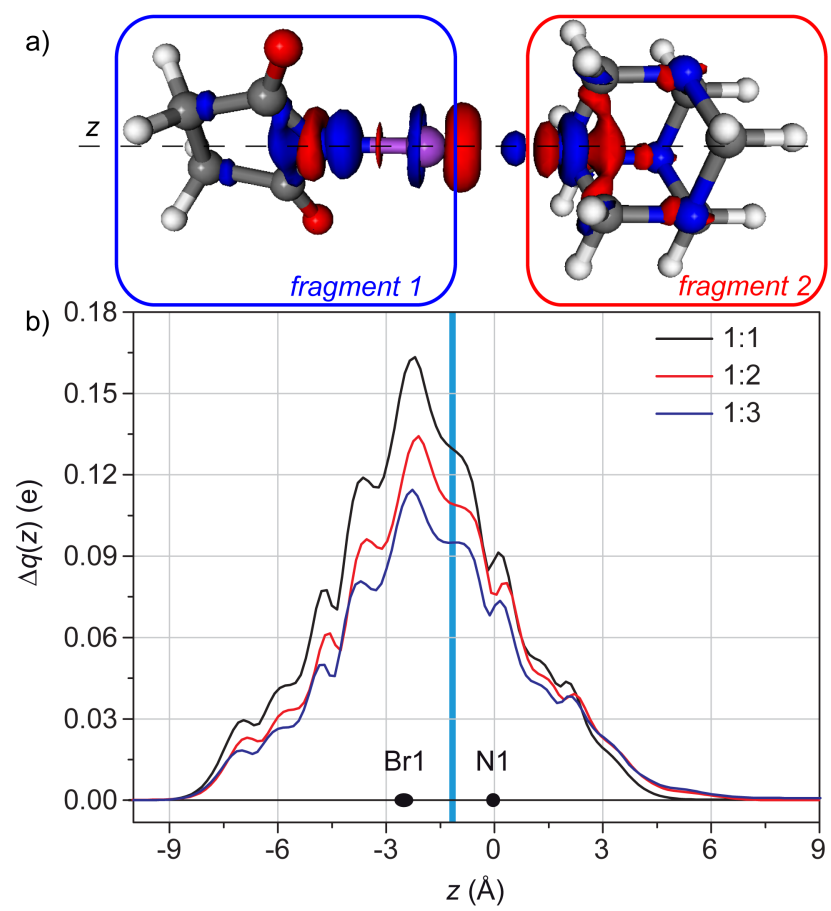

Figure 3. (a) 3D contour map of the change of electronic density upon formation of the adduct HMTA/NBS (1:1). Blue (red) isosurfaces identify regions in which the electron density increases (decreases). Density value at the isosurfaces: \pm 0.002 au. (b) Charge Displacement functions for HMTA/NBS adducts with different stoichiometry. The black dots represent the $z$ coordinate (or the range of coordinates) of the atoms. The light blue vertical band identifies the range of the interfragment boundaries.

Integrating $\Delta \rho$ along the axis containing the nitrogen of HMTA and the bromine of NBS $(z)$, the charge transfer $(C T)$ can be quantified as 0.130 e (Figure $3 \mathrm{~b}$ ).

Applying the same method to the $1: 2$ and 1:3 adducts, the corresponding $\Delta \rho$ maps reveal a qualitative similarity with the one calculated for the 1:1 adduct (Figure $4 \mathrm{a}$ and Figure S5, Supporting Information). This is reasonable, since in all the cases the interaction is similar. From the quantitative point of view, the integration of the $\Delta \rho$ functions leads to $C T$ values of 0.110 and 0.095 for the 1:2 and 1:3 adduct, respectively. The attenuation of the $C T$ as the number of NBS molecules around the central HMTA increases gives a framework to explain the attenuation of the formation constants: the four nitrogen atoms on the HMTA are not mutually independent, and the 
donation of electronic density from one nitrogen atom to a Lewis acid makes the donation properties of the non-involved nitrogen atoms lower.

This effect can be quantified applying the $\mathrm{CD}$ on a different axis. ${ }^{34}$ If we consider the adduct between HMTA and two NBS moieties, we obviously have two interactions between two different nitrogen atoms of the HMTA and the two molecules of NBS. They can be labeled N1 $\cdots$ NBS1 and N2 $\cdots$ NBS2. Taking as fragments NBS1 and HMTA/NBS2 and integrating $\Delta \rho$ along the axis containing N2 and the bromine of NBS2 (Figure 4), the effect of the establishment of N1 $\cdots$ NBS1 on N2 $\cdots$ NBS2 can be evaluated. In this case, the analysis of the $\Delta \rho$ shows that, upon the formation of N1 ${ }^{\cdots}$ NBS1, the nitrogen of NBS2 is located in a region of electron density depletion. This indicates a charge transfer from NBS2 to HMTA, leading to a XB weakening. The integration along the axis containing $\mathrm{N} 2$ and $\mathrm{Br} 2$ confirms the direction of the flux and leads to a weakening of $0.011 \mathrm{e}$ (Figure 4b).
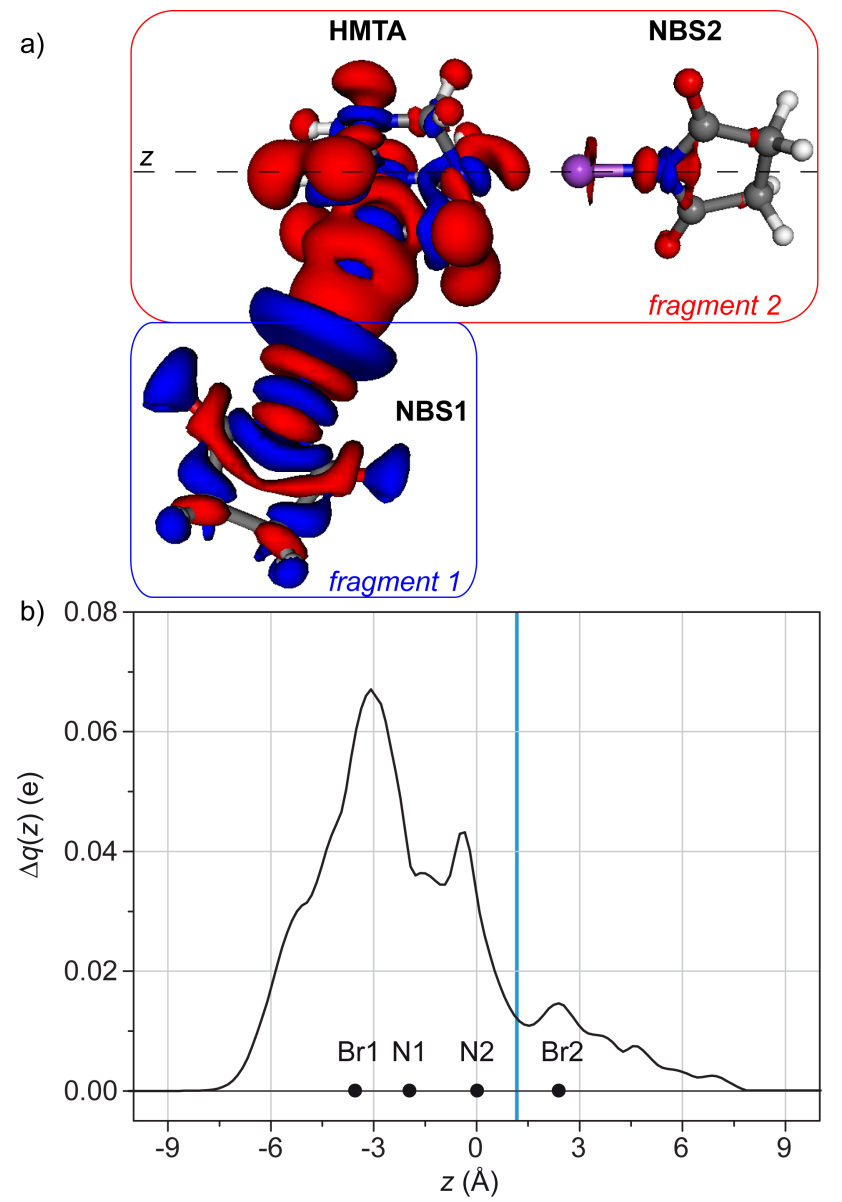
Figure 4. (a) 3D contour map of the change of electronic density upon formation of the adduct HMTA/NBS (1:2). Blue (red) isosurfaces identify regions in which the electron density increases (decreases). Density value at the isosurfaces: \pm 0.00025 au. (a) Charge Displacement functions for HMTA/NBS(1:2), integrated along the $\mathrm{N} 2{ }^{\cdots} \mathrm{Br} 2$ axis. The black dots represent the $z$ coordinate of the atoms. The light blue vertical band identifies the range of the inter-fragment boundaries.

The electronic energies $\Delta \mathrm{E}$ of the $1: 1,1: 2$ and 1:3 adducts are $-11.6,-20.5$ and $-28.0 \mathrm{kcal} / \mathrm{mol}$ (Supporting Information) with respect to the isolated components (see Table S1, Supporting Information). If we calculate $\Delta \mathrm{E} / \mathrm{n}$, where $\mathrm{n}$ is the number of NBS involved in the adduct, it results 11.6, -10.2 and $-9.3 \mathrm{kcal} / \mathrm{mol}$, respectively, again indicating that the interactions become weaker for larger aggregates (anti-cooperativity), in agreement with CD results. Therefore, the formation of adducts with higher stoichiometric ratios, as $1: 3$ and 1:4, is made difficult not only for obvious entropic reasons (each additional moiety loses its translational degree of freedom, making the $\Delta \mathrm{G}$ more positive), but also for enthalpic ones (the charge transfer becomes weaker as the number of units increases). Interestingly, in other cases the XB resulted to be cooperative in nature. ${ }^{35}$

DABCO/I3. A very intriguing combination is when both the acceptor and the donor are multi-site, and, in principle, any n:m adduct can exist. The pair $\mathbf{D A B C O / I 3 , ~ f o r ~ e x a m p l e , ~ i s ~ a b l e ~ t o ~ f o r m ~}$ infinite chains in the solid state. ${ }^{36}$ Also in this case the pair presents a low solubility, limiting the possibility to use non-stoichiometric solutions. Anyway, at least three different situations can be explored: an excess of DABCO, an excess of I3 and a substantial equivalence between the concentrations of the two components. In all the cases the solution is saturated, but both $V_{\mathrm{H}}(\mathbf{D A B C O})$ and $V_{\mathrm{H}}(\mathbf{I 3})$ are always much lower than $260 \AA^{3}$, which is the value of $V_{\mathrm{H}}^{\mathrm{agg}}(\mathbf{D A B C O}$, I3) (Table 6). Consequently, even if the presence of higher adducts cannot be excluded, their concentration should be very low in all cases. 
Table 6. Diffusion coefficients $\left(D_{\mathrm{t}}, 10^{-10} \mathrm{~m}^{2} \mathrm{~s}^{-1}\right)$ and hydrodynamic volumes $\left(V_{\mathrm{H}}, \AA^{3}\right)$ of DABCO / I3 mixtures in chloroform- $d$ at different concentrations $(C, \mathrm{mM})$.

\begin{tabular}{cccccc}
\hline$C(\mathbf{D A B C O})$ & $C(\mathbf{I 3})$ & $D_{\mathrm{t}}(\mathbf{D A B C O})$ & $D_{\mathrm{t}}(\mathbf{I 3})$ & $V_{\mathrm{H}}(\mathbf{D A B C O})$ & $V_{\mathrm{H}}(\mathbf{I 3})$ \\
\hline $85.8^{\mathrm{a}}$ & 7.8 & 13.0 & 10.8 & 123 & 175 \\
$29^{\mathrm{a}}$ & 21 & 12.6 & 11.8 & 159 & 180 \\
$16.7^{\mathrm{a}}$ & 58 & 12.2 & 13.5 & 178 & 146 \\
\hline solution & & & & &
\end{tabular}

${ }^{\text {a }}$ Saturated solution

Applying Eq. S1 and S2 (Supporting Information) to the experiments where one component is in excess $(C(\mathbf{D A B C O})=85.8$ and $C(\mathbf{I 3})=58 \mathrm{mM}$, Table 6$), K_{\mathrm{a} 1}$ results to be $6 \pm 2$ and $10 \pm 3 \mathrm{M}^{-1}$, respectively $\left(\Delta G_{\mathrm{a} 1}=-1.2 \mathrm{kcal} / \mathrm{mol}\right)$.

\section{Conclusions}

Diffusion NMR demonstrated to afford valuable information on the stoichiometry and the strength of the interactions of halogen-bonded adducts.

In particular, for the pair $\mathbf{M e}_{3} \mathbf{P y} / \mathbf{I} 1$ the complementarity of the NMR titration and the PGSE method allowed the estimation of the formation constant of the adducts held together by interactions different from the XB (non-XB).

In the case of the ditopic halogen acceptor DABCO, both 1:1 and 1:2 adducts have been directly detected, either using aliphatic and aromatic perfluorinated XB donors (I1 and I2). The corresponding formation constants have been evaluated and the formation of the 1:2 adduct showed an equilibrium constant considerably lower than that of the 1:1 adduct. For this system, the formation constant of the 1:1 adduct evaluated by NMR titration is in agreement with that measured by PGSE, indication that non-XB adducts are negligible. 
The case of HMTA is even more interesting, since it bears four symmetric nitrogen atoms and all of them potentially could establish an interaction with NBS. PGSE NMR data unequivocally demonstrate that only two nitrogen atoms are involved in the interaction with NBS and, again, the formation constant of the 1:2 adduct resulted lower than that of the 1:1 adduct. DFT and Charge Displacement investigations demonstrated that each molecule of NBS that binds on a nitrogen atom of the HMTA reduces the electron-donating properties of the other nitrogen atoms (anticooperativity).

Finally, PGSE NMR data demonstrated also that the interaction between DABCO and I3 is too weak in chloroform- $d$ to produce aggregates larger than the 1:1 adduct, despite both the $\mathrm{XB}$ acceptor and donor possess two binding sites and despite the existence in the solid state of infinite chains.

In conclusion, PGSE NMR can be surely considered a powerful technique, which gives information that could be a complement for the titration methods routinely used up to now. For this reason, an integrated multi-technique approach, which include titrations, diffusion and Overhauser NMR techniques (but also DFT calculations, when needed) is highly desirable, for a complete characterization of XB systems in solution.

\section{Acknowledgements}

Instituto de Física da Universidade Federal da Bahia is acknowledged for computational resources. C.Z. thanks the University of Perugia (Fondo Ricerca di Base 2014 D. D. n. 170, 23/12/2014) for financial support.

\section{Experimental Section}

All solvents and chemicals were purchased from Sigma-Aldrich and Cortecnet at the highest purity available and used as received. 1D and 2D NMR spectra were measured at $298 \mathrm{~K}$ on a Bruker DRX 
Avance 400 spectrometer equipped with a BBFO probe, on a Bruker Avance III HD 400 spectrometer equipped with a smartprobe. Referencing is relative to residual of undeuterated solvents $\left({ }^{1} \mathrm{H}\right)$ and $\mathrm{CCl}_{3} \mathrm{~F}\left({ }^{19} \mathrm{~F}\right)$.

PGSE NMR Measurements. ${ }^{1} \mathrm{H}$ and ${ }^{19} \mathrm{~F}$ PGSE NMR measurements were performed by using the double-stimulated echo sequence with longitudinal eddy current delay ${ }^{37}$ at $298 \mathrm{~K}$ without spinning. The dependence of the resonance intensity $(I)$ on a constant waiting time and on a varied gradient strength $G$ is described by the following equation:

$$
\ln \frac{I}{I_{0}}=(\gamma \delta)^{2} D_{t}\left(\Delta-\frac{\delta}{3}\right) G^{2}
$$

where $I$ is the intensity of the observed spin echo, $I_{0}$ the intensity of the spin echo in the absence of gradient, $\mathrm{D}_{\mathrm{t}}$ the self-diffusion coefficient, $\Delta$ the delay between the midpoints of the gradients, $\delta$ the length of the gradient pulse, and $\gamma$ the magnetogyric ratio. The shape of the gradients was rectangular, their length $\delta$ was $4-5 \mathrm{~ms}$, and their strength $G$ was varied during the experiments. All spectra were acquired for $32 \mathrm{k}$ points and a spectral width of $5000\left({ }^{1} \mathrm{H}\right)$ and $18000\left({ }^{19} \mathrm{~F}\right)$ and processed with a line broadening of 1.0. The semi-logarithmic plots of $\ln \left(I / I_{0}\right)$ versus $G^{2}$ were fitted by using a standard linear regression algorithm, and a correlation factor better than 0.99 was always obtained. Different values of $\Delta, G$, and number of transients were used for different samples.

The self-diffusion coefficient $D_{\mathrm{t}}$, which is directly proportional to the slope $\mathrm{m}$ of the regression line obtained by plotting $\ln \left(I / I_{0}\right)$ versus $G^{2}$, was estimated by evaluating the proportionality constant for a sample of $\mathrm{HDO}(5 \%)$ in $\mathrm{D}_{2} \mathrm{O}$ (known diffusion coefficients in the range 274-318 $\mathrm{K}^{38}$ ) under the exact same conditions as the sample of interest. The solvent or TMS was taken as internal standard. Computational Details. All the optimizations and thermodynamic calculations were performed using the Gaussian 09 program, ${ }^{39}$ using density functional theory employinghybrid metageneralized gradient approximation functional M06- $2 \mathrm{X}^{40}$ and the triple- $\zeta$ def2-TZVP basis set. The solvent and its polarity has been modeled through the PCM procedure (chloroform). ${ }^{41}$ All the 
optimized adducts show only positive vibrations, except hmta-3nbs, which showed three small uneliminable negative frequencies that could not be avoided during optimization. The negative vibrational modes were checked to make sure that they did not correspond to any motion along the halogen bond axes (bond formation or breaking). Rather, they refer to the rotation/vibration of the NBSs around the halogen bond axis.

All the Charge Displacement ${ }^{29}$ calculations were carried out using density functional theory employing the same level of calculation used for optimizations. Such an approach relies on the integration along a given direction $z$ (eq. 3) of the difference of electronic density $[\Delta \rho(x, y, z)]$ between the adduct and its non-interacting fragments, frozen in the same positions they occupy in the adduct.

$$
\Delta q\left(z^{\prime}\right)=\int_{-\infty}^{\infty} d x \int_{-\infty}^{\infty} d y \int_{-\infty}^{z^{\prime}} d z \Delta \rho(x, y, z)
$$

The value of $\Delta q\left(z^{\prime}\right)$ defines the amount of the electronic charge that, upon formation of the adduct, has moved across a plane perpendicular to the axis through the coordinate $z^{\prime}$. At the boundary between the fragments (the point on the $z$ axis at which equal-valued isodensity surfaces of the isolated fragments are tangent) the value of $\Delta q$ is represented by $C T$.

The electronic density matrices have been manipulated through the suite of tools "Cubes". 42

\section{References.}

${ }^{1}$ G. R. Desiraju, P. S. Ho, L. Kloo, A. C. Legon, R. Marquardt, P. Metrangolo, P. Politzer, G. Resnati and K. Rissanen, Pure Appl. Chem., 2013, 85, 1711.

2 (a) G. Berger, J. Soubhyea and F. Meyer, Polym. Chem., 2015, 6, 3559-3580; (b) L. C. Gilday, S. W. Robinson, T. A. Barendt, M. J. Langton, B. R. Mullaney and P. D. Beer, Chem. Rev., 2015, 115, 7118; (c) P. A. Gale and J. W. Steed, Supramolecular Chemistry: from molecules to nanomaterials, 
John Wiley \& Sons Ltd, New York, 1st edn, 2012; (d) G. Cavallo, P. Metrangolo, R. Milani, T. Pilati, A. Priimagi, G. Resnati and G. Terraneo, Chem. Rev., 2016, 116, 2478.

3 (a) E. Corradi, S. V. Meille, M. T. Messina, P. Metrangolo and G. Resnati, Angew. Chem. Int. Ed., 2000, 39, 1782; (b) P. Metrangolo, H. Neukirch, T. Pilati and G. Resnati, Acc. Chem. Res., 2005, 38, 386; (c) P. Metrangolo, F. Meyer, T. Pilati, G. Resnati and G. Terraneo, Angew. Chem., Int. Ed., 2008, 47, 6114; (d) P. Metrangolo, Y. Carcenac, M. Lahtinen, T. Pilati, K. Rissanen, A. Vij and G. Resnati, Science, 2009, 323, 1461.

${ }^{4}$ (a) F. Wang, N. Ma, Q. Chen, W. Wang and L. Wang, Langmuir, 2007, 23, 9540; (b) H. L. Nguyen, P. N. Horton, M. B. Hursthouse, A. C. Legon and D. W. Bruce, J. Am. Chem. Soc., 2004, 126, 16; (c) O. Bolton, D. Lee, J. Jung and J. Kim, Chem. Mater., 2014, 26, 6644; (d) S.-Q. Zang, Y.-J. Fan, J.-B. Li, H.-W. Hou and T. C. W. Mak, Cryst. Growth Des., 2011, 11, 3395.

${ }^{5}$ (a) M. Carter, A. R. Voth, M. R. Scholfield, B. Rummel, L. C. Sowers and P. S. Ho, Biochemistry, 2013, 52, 4891; (b) M. R. Scholfield, C. M. V. Zanden, M. Carter and P. S. Ho, Protein Science, 2013, 22, 139; (c) P. Zhou, F. Tian, J. Zou and Z. Shang, Mini-Reviews in Medicinal Chemistry, 2010, 10, 309.

${ }^{6}$ (a) L. P. Wolters, P. Schyman, M. J. Pavan, W. L. Jorgensen, F. M. Bickelhaupt and S. Kozuch, WIREs Comput. Mol. Sci., 2014, 4, 523; (b) S. Kozuch and J. M. L. Martin, J. Chem. Theory Comput., 2013, 9, 1918; (c) T. Clark, M. Hennemann, J. Murray and P. J. Politzer, J. Mol. Model., 2007, 13, 291; (d) P. Politzer, J. S. Murray and T. Clark, Phys. Chem. Chem. Phys., 2010, 12, 7748; (e) T. Clark, T. WIREs Comput. Mol. Sci. 2013, 3, 13-20; (f) S. M. Huber, E. Jimenez-Izal, J. M. Ugaldeb and I. Infante, Chem. Commun., 2012, 48, 7708; (g) C. Wang, D. Danovich, Y. Mo and S. Shaik, J. Chem. Theory Comput. 2014, 10, 3726.

7 (a) A. Bruckmann, M. Pena and C. Bolm, Synlett, 2008,2008, 900; (b) S. M. Walter, F.Kniep, E.Herdtweck and S. M. Huber, Angew. Chem. Int. Ed., 2011, 50, 7187; (c) S.Dordonne, B.Crousse, D. Bonnet-Delpon and J.Legros, Chem. Commun., 2011, 47, 5855;(d) Lefèvre, G. Franc, C. Adamo, A. Jutand and I. Ciofini, Organometallics 2012, 31, 914; (e) S. H. Jungbauer,S. M. Walter, S. Schindler, L. Rout, F.Kniepa and S. M. Huber, Chem. Commun., 2014, 50, 6281; (f) D. P. de Sousa, C.Wegeberg, M. S.Vad, S Mørup,C. Frandsen, W. A. Donald and Christine J. McKenzie, Chem. Eur. J. 2016, 22, 3810; (g) V. P. N. Nziko and S. Scheiner, J. Org. Chem., 2016, 81, 2589.

${ }^{8}$ (a) M. J. Langton, I. Marques, S. W. Robinson, V. Félix and P. D. Beer, Chem. Eur. J., 2016, 22, 185; (b) S. W. Robinson, C. L. Mustoe, N. G. White, A. Brown, A. L. Thompson, P.Kennepohl and P. D. Beer, J. Am. Chem. Soc., 2015, 137, 499; (c) M. G. Sarwar, B. Dragisic, S. Sagoo and M. S. Taylor, Angew. Chem. Int. Ed., 2010, 49, 1674. 
${ }^{9}$ (a) K. Gao and N. S. Goroff, J. Am. Chem. Soc., 2000, 122, 9320; P. D. Rege, O. L. Malkina and N. S. Goroff, J. Am. Chem. Soc., 2002, 124, 370; (b) N. Ma, Y. Zhang, B. Ji, A. Tian and W. Wang, ChemPhysChem, 2012, 13, 1411.

${ }^{10}$ (a) G. Bellachioma, B. Binotti, G. Cardaci, C. Carfagna, A. Macchioni, S. Sabatini and C. Zuccaccia, Inorg. Chim. Acta, 2002, 330, 44, (b) G. Ciancaleoni, L. Belpassi, F. Tarantelli, D. Zuccaccia and A. Macchioni, Dalton Trans., 2013, 42, 4122.

${ }^{11}$ L. Rocchigiani, G. Ciancaleoni, C. Zuccaccia and A. Macchioni, J. Am. Chem. Soc., 2014, 136, 112.

${ }^{12}$ G. Ciancaleoni, R. Bertani, L. Rocchigiani, P. Sgarbossa, C. Zuccaccia and A. Macchioni, Chem. Eur. J., 2015, 21, 440.

${ }^{13}$ M. Erdély, Chem. Soc. Rev., 2012, 41, 3547 and references within.

${ }^{14}$ S. H. Jungbauer, S. Schindler, E. Herdtweck, S. Keller and S. M. Huber, Chem. Eur. J., 2015, 21, 13625.

${ }^{15}$ P. Thordarson, Chem. Soc. Rev., 2011, 40, 1305.

${ }^{16}$ (a) G. Bellachioma, G. Ciancaleoni, C. Zuccaccia, D. Zuccaccia and A. Macchioni, Coord. Chem. Rev., 2008, 252, 2224; (b) P. S. Pregosin, Spectroscopic Properties of Inorganic and Organometallic Compounds: Techniques, Materials and Applications, 2011, 42, 248; (c) L. Avram and Y. Cohen, Chem. Soc. Rev., 2015, 44, 586; (d) L. Rocchigiani and A. Macchioni, Dalton Trans., 2016, 45, 2785; (e) P. S. Pregosin, Magn. Reson. Chem. DOI: 10.1002/mrc. 4394.

${ }^{17}$ A. Macchioni, G. Ciancaleoni, C. Zuccaccia and D. Zuccaccia, Chem. Soc. Rev., 2008, 37, 479.

18 (a) A.-C. C. Carlsson, J. Gräfenstein, A. Budnjo, J. L. Laurila, J. Bergquist, A. Karim, R. Kleinmaier, U. Brath and M. Erdélyi, J. Am. Chem. Soc., 2012, 134, 5706; (b) M. Bedin, A. Karim, M. Reitti, A-C C. Carlsson, F. Topić, M. Cetina, F. Pan, V. Havel, F. Al-Ameri, V. Sindelar, K.Rissanen, J.Gräfenstein and M.Erdély, Chem. Sci., 2015, 6, 3746.

${ }^{19}$ During the evaluation process of the present paper, other two articles that use diffusional NMR techniques on XB systems have been published: (a) L. Maugeri, J. Asencio-Hernandez, T. Lébl, D.

B. Cordes, A. M. Z. Slawin, M.-A. Delsuc and D. Philp, Chem. Sci., DOI: 10.1039/c6sc01974a; (b) C. J. Massena, N. B. Wageling, D. A. Decato, E. M. Rodriguez, A. M. Rose and O. B. Berryman, Angew. Chem. Int. Ed., DOI: 10.1002/anie.201605440.

${ }^{20}$ (a) L. Rocchigiani, G. Bellachioma, G. Ciancaleoni, S. Crocchianti, A. Laganá, C. Zuccaccia, D. Zuccaccia and A. Macchioni, ChemPhysChem, 2010, 11, 3243; (b) G. Ciancaleoni, I. Di Maio, D. Zuccaccia and A. Macchioni, Organometallics, 2007, 26, 489.

${ }^{21}$ L. Fielding, Tetrahedron, 2000, 56, 6151. 
${ }^{22}$ For I1 and DABCO, see: (a) R. Cabot and C. A. Hunter, Chem. Commun., 2009, 2005; for I2, see: (b) M. G. Sarwar, B. Dragisic, L. J. Salsberg, C. Gouliaras and M. S. Taylor, J. Am. Chem. Soc., 2010, 132, 1646; for I3, see ref 3d; for NBS and hmta, see: (c) K.Raatikainen and K.Rissanen, CrystEngComm, 2011, 13, 6972; for $\mathbf{M e}_{3} \mathbf{P y}$, see: (d) C. Laurence, J. Graton, M. Berthelot and M. J. El Ghomari, Chem. Eur. J., 2011, 17, 10431.

${ }^{23}$ (a) R. B. Walsh, C. W. Padgett, P. Metrangolo, G.Resnati, T. W. Hanks and W. T. Pennington, Cryst. Growth Des., 2001, 1, 165; (b) C. Perkins, S. Libri, H. Adams and L. Brammer, CrystEngComm, 2012, 14, 3033; (c) L. Catalano, S. Perez-Estrada, G. Terraneo, T. Pilati, G. Resnati, P. Metrangolo and M. A. Garcia-Garibay, J. Am. Chem. Soc., 2015, 137, 15386.

${ }^{24}$ E. Corradi, S. V. Meille, M. T. Messina, P. Metrangolo and G. Resnati, Angew. Chem. Int. Ed., 2000, 39, 1782.

${ }^{25} K_{\mathrm{a}}$ for the pair Py/I1 in benzene results to be 1.0, see ref. 22a.

${ }^{26}$ A. Wasilewska, M. Gdaniec and T Połoński, CrystEngComm, 2007, 9, 203.

${ }^{27} K_{\mathrm{a}}$ for the pair $\mathbf{D A B C O} / \mathbf{I 1}$ in benzene results to be 32, see ref. 22a.

${ }^{28}$ S. Kozuch and J. M. L. Martin, J.Chem. Theory Comput., 2013, 9, 1918.

${ }^{29}$ L. Belpassi, I. Infante, F. Tarantelli and L. Visscher, J. Am. Chem. Soc. 2008, 130, 1048.

${ }^{30}$ (a) G. Ciancaleoni, L. Biasiolo, G. Bistoni, A. Macchioni, F. Tarantelli, D. Zuccaccia and L. Belpassi, Chem. Eur. J. 2015, 21, 2467; (b) G. Ciancaleoni, N. Scafuri, G. Bistoni, A. Macchioni, F. Tarantelli, D. Zuccaccia and L. Belpassi, Inorg. Chem. 2014, 53, 9907; (c) G. Bistoni, S. Rampino, N. Scafuri, G. Ciancaleoni, D. Zuccaccia, L. Belpassi and F. Tarantelli, Chem., Sci.2016, 7, 1144.

${ }^{31}$ D. Cappelletti, E. Ronca, L. Belpassi, F. Tarantelli and F. Pirani, Acc. Chem. Res. 2012, 45, 1571. 32 (a) D. Cappelletti, A. Bartocci, F. Grandinetti, S. Falcinelli, L. Belpassi, F. Tarantelli and F. Pirani, Chem. Eur. J. 2015, 21, 6234; (b) A. Bartocci, L. Belpassi, D. Cappelletti, S. Falcinelli, F. Grandinetti, F. Tarantelli and F. Pirani, J. Chem. Phys. 2015, 142, 184304; (c) G. Ciancaleoni, M. Arca, G. F. Caramori, G. Frenking, F. S. S. Schneider and V. Lippolis, Eur. J. Inorg Chem., 2016, 23, 3804 .

${ }^{33}$ G. Ciancaleoni, C. Santi, M. Ragni and A. L. Braga, Dalton Trans., 2015, 44, 20168.

${ }^{34}$ K. M. Lemishko, G. Bistoni, L. Belpassi, F. Tarantelli, M. M. Montero-Campillo and M. Yáñez (2016), Charge Transfer in Beryllium Bonds and Cooperativity of Beryllium and Halogen Bonds. A New Perspective in R. Chauvin et al. (Eds.) Applications of Topological Methods in Molecular Chemistry (461-489) Springer Ed., Switzerland.

35 J. George, V. L. Deringer and R. Dronskowski, J. Phys. Chem. A, 2014, 118, 3193. 
${ }^{36}$ P. Cardillo, E. Corradi, A. Lunghi, S. V.Meille,M. T. Messina, P.Metrangolo and G.Resnati, Tetrahedron, 2000, 56, 5535.

${ }^{37}$ A. Jerschow and N. Müller, J. Magn. Reson., 1997, 125, 372.

${ }^{38}$ R. Mills, J. Phys. Chem. 1973, 77, 685.

39 M. J. Frisch, G. W. T., H. B. Schlegel, G. E. Scuseria, M. A. Robb, J. R. Cheeseman, G.Scalmani, V. Barone, B. Mennucci, G. A. Petersson, H. Nakatsuji, M. Caricato, X. Li, H. P. Hratchian, A. F. Izmaylov, J. Bloino, G. Zheng, J. L. Sonnenberg, M. Hada, M. Ehara, K. Toyota, R. Fukuda, J. Hasegawa, M. Ishida, T. Nakajima, Y. Honda, O. Kitao, H. Nakai, T. Vreven, J. A. Montgomery, Jr., J. E. Peralta, F. Ogliaro, M. Bearpark, J. J. Heyd, E. Brothers, K. N. Kudin, V. N. Staroverov, T. Keith, R. Kobayashi, J. Normand, K. Raghavachari, A. Rendell, J. C. Burant, S. S. Iyengar, J. Tomasi, M. Cossi, N. Rega, J. M. Millam, M. Klene, J. E. Knox, J. B. Cross, V. Bakken, C. Adamo, J. Jaramillo, R. Gomperts, R. E. Stratmann, O. Yazyev, A. J. Austin, R. Cammi, C. Pomelli, J. W. Ochterski, R. L. Martin, K. Morokuma, V. G. Zakrzewski, G. A. Voth, P. Salvador, J. J. Dannenberg, S. Dapprich, A. D. Daniels, O. Farkas, J. B. Foresman, J. V. Ortiz, J. Cioslowski, and D. J. Fox,, Gaussian 09, Gaussian, Inc., Wallingford CT, 2013.

${ }^{40}$ Y. Zhao and D. Truhlar, Theor. Chem. Acc., 2008, 120, 215.

41 J. Tomasi, B. Mennucci, R. Cammi, Chem. Rev. 2005, 105, 2999-3094.

${ }^{42}$ S. Rampino, VIRT\&L-COMM, 2015, 7, 6. 